\title{
Kebijakan Penggunaan Media Online Website Kompas TV Dan Youtube Untuk Menyalurkan Konten "Eksklusif Digital" Kompas TV
}

\author{
Finna Prima Handayani dan Ika Merdekawati \\ Program Studi Jurnalistik, Fakultas Ilmu Komunikasi, Universitas Padjadjaran \\ Email : finna.prima@gmail.com
}

\begin{abstract}
Abstrak
Meningkatnya konsumsi internet oleh masyarakat Indonesia berdampak pada perubahan pola pemenuhan kebutuhan akan informasi. Kini, masyarakat Indonesia lebih memanfaatkan media online ketika mencari informasi yang dibutuhkan. Hal itu berpengaruh pada penurunan jumlah khalayak yang menggunakan media massa konvensional, termasuk khalayak yang menonton tayangan televisi konvensional. Dengan demikian, Kompas $T V$ membuat sebuah tayangan digital berbasis internet, yaitu "Eksklusif Digital" yang memanfaatkan kanal website kompas.tv dan YouTube untuk menyalurkan kontennya. Penelitian ini menggunakan metode Studi Kasus Intrinsik Robert E. Stake dengan teknik pengumpulan data berupa wawancara, observasi, studi dokumen, dan studi pustaka. Hasil penelitian adalah Kompas TV menggunakan website kompas.tv dan YouTube untuk penyaluran konten "Eksklusif Digital", karena website kompas.tv merupakan platform utama Kompas TV dalam media online dan bertujuan untuk memperkenalkan website kompas.tv kepada khalayak sebagai video portal Kompas TV. Kemudian menggunakan YouTube, karena saat ini YouTube merupakan media sosial yang paling aktif digunakan di Indonesia.
\end{abstract}

Kata Kunci: Konvergensi, Media Online, Media Penyiaran, New Media, YouTube.

\begin{abstract}
The increasing of internet cosumption by Indonesian people has an impact to alteration pattern of fulfilling demanding information. Nowadays, Indonesian people take more advantages from online media to look for such information that they need. It affects the declining amount of poeple using conventional mass media, including those who watch convenstional television program. Therefore, Kompas TV produces an internet-based digital program called "Eksklusif Digital" which uses kompas.tv and YouTube website channels to distribute its content. This research uses Robert E. Stake's Intrinsic Case Study method with data collection technique in forms of interview, obervation, document study, and literature study. The result of this research is Kompas TV uses kompas.tv and YouTube websites for "Eksklusif Digital" content distribution, since kompas.tv website is Kompas TV's main platform in online media and is aimed to introduce kompas.tv website to people as Kompas TV's video portal. Then, the use of YouTube, since it is currently the most active social media used in Indonesia.
\end{abstract}

Key Words : Convergence, Online Media, Broadcasting, New Media, YouTube.

http://jurnal.unpad.ac.id/kajian-jurnalisme 
Kajian Jurnalisme ISSN 2549-0559 (cetak) ISSN 2549-1946 (online)

Volume 02 Nomor 02 Tahun 2019

\section{Pendahuluan}

Fenomena konsumsi internet oleh masyarakat Indonesia kini semakin meningkat, khususnya dalam beberapa tahun terakhir. Berdasarkan data dari www.eMarketer.com, pada tahun 2017 Indonesia tercatat berada pada peringkat enam besar sebagai negara pengguna internet terbanyak di dunia, setelah China, US, India, Brazil, dan Jepang. Perkembangan konsumsi internet di Indonesia yang semakin meningkat, hal itu memengaruhi terhadap lahirnya smartphone sebagai perangkat yang digunakan untuk mengakses internet. Kehadiran smartphone ini mulai menguasai masyarakat Indonesia dan menyalip keberadaan media massa di Indonesia, baik media cetak maupun elektronik.

Dengan adanya perkembangan internet yang semakin pesat dan hadirnya smartphone, berdampak pada perubahan budaya masyarakat dalam pemenuhan kebutuhan akan informasi. Biasanya masyarakat Indonesia memenuhi kebutuhan informasi melalui media cetak atau media elektronik, tapi kini masyarakat memanfaatkan jaringan internet dan smartphone untuk mencari informasi yang mereka butuhkan. Sebagai contoh, dahulu masyarakat Indonesia sering menonton tayangan atau program berita pada siaran televisi terestrial, tapi kini ketika internet dan smartphone mulai dikenal oleh masyarakat Indonesia, mereka memanfaatkan kedua hal tersebut untuk melakukan streaming program televisi terestrial melalui smartphone yang dimiliki. Sehingga penonton televisi konvensional di Indonesia mulai berkurang. Lembaga survey Nielsen mencatat pada tahun 2013 terdapat peningkatan lebih dari 25\% khalayak usia 18 hingga 34 tahun menggunakan smartphone untuk melakukan streaming tayangan televisi. Hal itu berpengaruh pada penurunan jumlah penonton televisi konvensional sebanyak 10\%, dari sekitar 8,5 juta orang per menit menjadi 8,4 juta orang per menit.

Saat ini Indonesia sedang masuk dalam era digital berbasis internet. Masyarakat Indonesia lebih menyukai menonton tayangan-tayangan digital berbasis internet, dibandingkan menonton tayangan pada siaran televisi konvensional. YouTube merupakan sebuah video portal yang sering dijadikan alternatif masyarakat Indonesia dalam mengakses tayangan digital berbasis internet. Kelebihan YouTube yang dapat diakses oleh siapapun, di manapun, dan kapanpun membuat penonton YouTube di Indonesia semakin bertambah. CEO YouTube Susan Wojcicki, menuturkan pada tahun 2017 ini penonton YouTube lebih banyak daripada penonton televisi Indonesia. Jumlah penonton YouTube di usia 18 hingga 49 tahun berhasil mengalahkan jumlah penonton di rentang usia yang sama di platform lain, baik siaran televisi konvensional ataupun siaran televisi kabel. Menurutnya, mereka berhasil menjangkau penonton berumur 18 hingga 49 tahun lebih banyak daripada total penonton yang dicapai oleh 10 acara TV terpopuler. (http://m.metrotvnews.com/teknologi/news-teknologi/ Obz9BJeN-bos-youtube-penonton-tvberkurang-penonton-kami-bertambah, diakses pada 4 Juli 2017)

http://jurnal.unpad.ac.id/kajian-jurnalisme 
Kajian Jurnalisme

ISSN 2549-0559 (cetak) ISSN 2549-1946 (online)

Volume 02 Nomor 01 Tahun 2019

Seiring bertambahnya jumlah masyarkat Indonesia yang lebih sering mengakses YouTube atau menonton tayangan digital berbasis internet, hal tersebut membuat kekhawatiran terhadap siaran televisi konvensional. Eksistensi televisi konvensional bisa saja meredup apabila masyarakat Indonesia beralih pada tontonan digital berbasis internet. Dengan demikian, saluran televisi konvensional harus bisa menyesuaikan diri dengan perkembangan teknologi yang ada. Tujuannya agar siaran televisi tetap bisa menjaga eksistensinya di kalangan masyarakat. Hal yang dapat dilakukan untuk menjaga eksistensi siaran televisi yaitu membut inovasi program/tayangan yang dapat pula diakses dengan menggunakan jaringan internet, artinya membuat seperti tayangan digital berbasis internet. Sehingga siaran televisi tetap bisa berjalan beriringan dengan tayangan versi digital berbasis internet lainnya.

Adanya tayangan digital berbasis internet tersebut berpengaruh pada lahirnya new media atau media baru. New media memiliki karakteristik: (1) Sudah masuk ke era digital, yang kemudian memungkinkan perbedaan format media itu menjadi samar seperti antara cetak dan elektronik, karena keduanya dapat dilewatkan melalui saluran yang sama, (2) Sudah mempunyai sifat interaktif, (3) Sudah tidak mengenali lagi batas-batas wilayah negara. (Severin, 2008)

Sementara dalam kaitan dengan dunia penyiaran, Canadian Broadcasting Corporation (CBC) menjelaskan new media bagi dunia penyiaran adalah proses streaming di jaringan internet atau mobile. Lebih jelasnya, new media adalah satu media yang menggunakan media lain selain udara, sementara kontennya tetap penyiaran. Salah satu stasiun televisi di Indonesia menerapkan konsep new media adalah Kompas TV dengan membuat tayangan bernama "Eksklusif Digital".

"Eksklusif Digital" merupakan sebuah tayangan yang khusus/hanya disalurkan melalui media online, yaitu kanal website kompas.tv dan YouTube. Bernama "Eksklusif Digital" pun karena, kontennya yang eksklusif yaitu hanya ditayangakan pada program-program "Eksklusif Digital", tidak ditayangkan pada program-program Kompas TV terestrial. Sehingga khalayak yang ingin menonton tayangannya, harus membuka website kompas.tv atau YouTube Kompas $T V$, karena "Eksklusif Digital” tidak ada pada tayangan Kompas TV terestrial.

Hal yang mendasari dibuatnya "Eksklusif Digital", berdasarkan wawancara dengan Haris Mahardiansyah selaku pihak dari Departemen Digital Kompas TV, mengaku jika saat ini penonton televisi, khususnya anak muda, sudah mulai berkurang jumlahnya. Mereka lebih sering mengakses YouTube daripada menonton televisi. Oleh karena itu, "Eksklusif Digital" memanfaatkan kanal website kompas.tv dan YouTube untuk menyalurkan kontennya kepada khalayak. Jenis tayangan seperti "Eksklusif Digital" saat ini hanya ada di Kompas TV, media atau televisi pesaing belum memilikinya. Sebab, umumnya stasiun televisi lain memiliki konten tayangan yang sama pada siaran televisi terestrial dan pada tayangan digital berbasis internet, yaitu pada website dan YouTube. Hingga saat ini, "Eksklusif Digital" memiliki lima program, yaitu Musika Foresta, Cerita Indonesia, Top 3 News, News Vlog, dan Web Series Izinkan Kami Sekolah.

http://jurnal.unpad.ac.id/kajian-jurnalisme 
201 | Kajian Jurnalisme

ISSN 2549-0559 (cetak) ISSN 2549-1946 (online)

Volume 02 Nomor 02 Tahun 2019

Sebagai media televisi konvensional di Indonesia yang pertama membuat jenis tayangan seperti "Eksklusif Digital" yang hanya memanfaatkan media online, yaitu website kompas.tv dan YouTube untuk penyaluran kontennya, timbul pertanyaan awal peneliti yang mendasari adanya penelitian ini, yaitu apakah yang membuat Kompas $T V$ memilih menggunakan kanal website kompas.tv dan YouTube sebagai penyaluran konten "Eksklusif Digital" dan tidak menggunakan kanal media online lainnya? Dengan demikian, hal yang diteliti dalam penelitian ini, yaitu mengenai kebijakan memilih media online website kompas.tv dan YouTube sebagai sarana untuk menyalurkan konten "Eksklusif Digital” Kompas TV.

Mediamorfosis merupakan pisau analisis dari penelitian ini. Mediamorfosis relevan dengan penelitian ini karena berkaitan dengan perubahan media komunikasi, yang awalnya dari tayangan siaran televisi konvensional menjadi tayangan berbasis internet yang dapat diakses melalui smartphone. Hal itu terjadi karena adanya inovasi teknologi yang semakin maju, dan tekanan persaingan di era digital yang nampaknya seiring berjalannya waktu bisa menggerus keberadaan tayangan siaran televisi konvensional.

\section{Metode}

Metode penelitian adalah tata cara bagaimana suatu penelitian akan dilaksanakan. Metode penelitian membicarakan mengenai tata cara pelaksanaan penelitian. Dengan demikian, metode penelitian melingkupi prosedur penelitian dan teknik penelitian. Selain itu, metodologi adalah proses, prinsip, dan prosedur yang kita gunakan untuk mendekati problem dan mencari jawaban. Dengan kata lain, metodologi adalah suatu pendekatan umum untuk mengkaji topik penelitian.

Metode penelitian pada dasarnya merupakan cara ilmiah untuk mendapatkan data dengan tujuan dan kegunaan tertentu. Setiap penelitian mempunyai tujuan dan kegunaan tertentu. Secara umum tujuan penelitian ada tiga macam, yaitu yang bersifat penemuan, pembuktian, dan pengembangan. Sedangkan kegunaan, secara umum data yang telah diperoleh dari penelitian dapat digunakan untuk memahami, memecahkan, dan mengantisipasi masalah. Berdasarkan tingkat kealamiahan, metode penelitian dapat dikelompokkan menjadi metode penelitian eksperimen, survey, dan naturalistik. Metode penelitian eksperimen dan survey termasuk dalam metode kuantitatif, sedangkan metode naturalistik termasuk dalam metode kualitatif (Sugiyono, 2012: 2-4).

Pada penelitian ini digunakan metode penelitian kualitatif. Moleong (2012: 6) mendefinisikan penelitian kualitatif sebagai penelitian yang bermaksud untuk memahami fenomena tentang apa yang dialami oleh subjek penelitian (perilaku, motivasi, dan tindakan) secara holistik dan dengan cara deskripsi dalam bentuk kata-kata dan bahasa, pada suatu konteks

http://jurnal.unpad.ac.id/kajian-jurnalisme 
Kajian Jurnalisme

ISSN 2549-0559 (cetak) ISSN 2549-1946 (online)

Volume 02 Nomor 01 Tahun 2019

khusus yang alamiah dan dengan memanfaatkan berbagai metode alamiah. Sementara pendekatan yang digunakan pada penelitian ini yaitu studi kasus.

Studi kasus adalah salah satu metode penelitian ilmu-ilmu sosial. Secara umum, studi kasus merupakan strategi yang lebih cocok bila pokok pertanyaan suatu penelitian berkenaan dengan how (bagaimana) dan why (mengapa), bila peneliti hanya memiliki sedikit peluang untuk mengontrol peristiwa-peristiwa yang akan diselidiki, dan bilamana fokus penelitiannya terletak pada fenomena kontemporer (masa kini) di dalam konteks kehidupan nyata (Yin, 2014: 1). Sedangkan menurut Stake (Denzin \& Lincoln, 1994) nama studi kasus ditekankan oleh beberapa peneliti karena memfokuskan tentang apa yang dapat dipelajari secara khusus pada kasus tunggal.

Penekanan studi kasus adalah memaksimalkan pemahaman tentang kasus yang dipelajari dan bukan untuk mendapatkan generalisasi. Stake mengidentifikasikan studi kasus ke dalam tiga tipe. Ketiga tipe tersebut adalah studi kasus intrinsik, studi kasus instrumental, dan studi kasus kolektif. Menurut Stake (2010: 447) tujuan kategorisasi yang dilakukannya bukanlah taksonomik, melainkan untuk menekankan variasi terkait dan orientasi metodologis terhadap kasus.

1. Studi kasus intrinsik, yaitu studi untuk mendapatkan pemahaman yang lebih baik dari kasus yang khusus. Hal ini disebabkan karena seluruh kekhususan dan keluarbiasaan kasus itu sendiri menarik perhatian.

2. Studi kasus instrumental, yaitu kasus khusus yang diuji untuk memberikan pemahaman yang mendalam tentang suatu masalah (issue) atau untuk memperbaiki teori yang telah ada.

3. Studi kasus kolektif, yaitu penelitian terhadap gabungan kasus-kasus dengan maksud meneliti fenomena, populasi, atau kondisi umum.

Pada penelitian ini, metode studi kasus merupakan yang tepat untuk digunakan. Sebab, strategi studi kasus cocok untuk diterapkan pada penelitian yang berkaitan dengan tipe pertanyaan why (mengapa) dan how (bagaimana).

Dari tiga tipe studi kasus menurut Stake, penelitian ini menggunakan tipe studi kasus intrinsik. Studi kasus intrinsik yaitu studi untuk mendapatkan pemahaman yang lebih baik dari kasus yang khusus. Hal ini disebabkan karena seluruh kekhususan dan keluarbiasaan kasus itu sendiri menarik perhatian. Menggunakan metode studi kasus intrinsik, karena pada penelitian ini sudah teridentifikasi kasus dengan jelas, yaitu berkurangnya jumlah penonton tayangan televisi konvensional dan mulai beralih pada tontonan digital berbasis internet, seperti tontonan pada website dan YouTube, sehingga dibuatlah "Eksklusif Digital" Kompas TV yang merupakan tayangan digital berbasis internet yang saat ini baru dimiliki oleh Kompas $T V$.

http://jurnal.unpad.ac.id/kajian-jurnalisme 
203 | Kajian Jurnalisme

ISSN 2549-0559 (cetak) ISSN 2549-1946 (online)

Volume 02 Nomor 02 Tahun 2019

Selanjutnya teknik pengumpulan data yang digunakan pada penelitian ini adalah wawancara, dengan tiga orang informan yaitu Yogi Nugraha selaku GM News \& Current Affairs Kompas TV, Haris Mahardiansyah selaku Content Creator \& Video Distribution Superintendent Departemen Digital Kompas TV, dan Inne Nathalia selaku Socmed Strategiest \& Community Superintendent Departemen Digital Kompas $T V$. Kemudian observasi pada pengelolaan "Eksklusif Digital" dan pada tayangan "Eksklusif Digital" di website kompas.tv dan YouTube. Serta, studi dokumen mengenai profil Kompas TV, deskripsi tayangan "Eksklusif Digital", struktur Departemen Digital Kompas TV, jumlah penonton "Eksklusif Digital”, dan dokumen tayangan dari setiap program "Eksklusif Digital". Pun tak luput studi pustaka dari berbagai sumber, seperti buku-buku referensi, jurnal penelitian, laporan-laporan, dan media lainnya yang masih berkaitan dengan topik penelitian.

\section{Hasil dan Pembahasan}

Pada Maret 2017, Kompas TV untuk pertama kalinya menayangkan "Eksklusif Digital" yang merupakan program khusus digital berbasis internet yang kontennya hanya ditayangkan pada kanal website kompas.tv dan YouTube Kompas TV. Konten "Eksklusif Digital” tidak ditayangkan pada siaran televisi terestrial Kompas TV, karena memang dari awal kemunculannya, "Eksklusif Digital" khusus disiapkan untuk tayangan digital berbasis internet. "Eksklusif Digital" Kompas $T V$ ini dikelola oleh Departemen Digital Kompas TV. "Eksklusif Digital” memiliki lima program, yaitu Top 3 News, Cerita Indonesia, News Vlog, Musika Foresta, dan terdapat program baru saat pengumpulan data yaitu Web Series Izinkan Kami Sekolah.

Untuk jenis kontennya, "Eksklusif Digital" termasuk dalam berita lunak (softnews), yang terdiri dari current affairs, magazines, dokumenter, dan talk show. Dari berbagai tayangan tersebut memiliki sasaran khalayak yang sama, yaitu mengarah pada segmentasi ABC atau kalangan menengah di usia 15 tahun sampai dengan 40 tahun.

Menurut penuturan Inne Nathalia, Socmed Strategiest \& Community Superintendent Departemen Digital Kompas TV, awal keberadaan "Eksklusif Digital" ini karena adanya ajakan kerjasama kepada Kompas TV yang ditawarkan oleh suatu LSM bernama Hutan Itu Indonesia, di mana LSM tersebut ingin membuat sebuah konten acara yang mengajak orang-orang terkenal dalam hal ini yaitu musisi untuk masuk ke dalam hutan lalu membuat musik di sana dan ketika kembali ke Jakarta atau kotanya masing-masing, musisi yang diajak itu akan menghasilkan karya dalam bentuk konser. LSM Hutan Itu Indonesia mempercayakan kepada Kompas TV untuk menggagas jenis tayangan sesuai dengan yang LSM Hutan Itu Indonesia inginkan.

Awalnya, pihak Kompas TV merasa konten yang diinginkan oleh LSM tersebut di luar dari konsep tayangan Kompas $T V$ terestrial yang selama ini telah ada, dan dengan alasan tertentu

http://jurnal.unpad.ac.id/kajian-jurnalisme 
Kajian Jurnalisme

ISSN 2549-0559 (cetak) ISSN 2549-1946 (online)

Volume 02 Nomor 01 Tahun 2019

Kompas $T V$ mustahil untuk membuatkan sebuah program seperti itu di siaran televisi teresterial. Akhirnya dengan berbagai pertimbangan, konten tayangan tersebut didistribusikan di digital Kompas TV. Dari situlah awal munculnya "Eksklusif Digital" Kompas TV.

Selain itu, kebijakan utama Kompas TV memilih kanal website kompas.tv dan YouTube sebagai medium penyaluran konten "Eksklusif Digital" karena website kompas.tv merupakan platform utama Kompas TV pada media online (dalam jaringan). Dengan menggunakan kanal website kompas.tv pun bertujuan untuk lebih memperkenalkan website kompas.tv kepada khalayak sebagai video portal dari Kompas $T V$.

"Bahwa kita ini kan sekarang sedang membangun website kita, berubah dari sekadar untuk informasi corporate, maksudnya tentang program acara, lowongan kerja, menjadi video portal. Which is itu menjadi saluran untuk menampung konten-konten Kompas $T V$, tapi materinya bisa digunakan juga untuk website. Mengapa kita memilih website, karena itu main platform kita," (Wawancara peneliti dengan Yogi Nugraha, GM News \& Current Affairs Kompas TV pada 4 September 2017).

Lalu, kanal lainnya yang digunakan sebagai medium penyaluran konten "Eksklusif Digital" yaitu YouTube. Menurut GM News \& Current Affairs Kompas TV Yogi Nugraha, memilih YouTube karena memang pengunjung YouTube saat ini adalah yang paling tinggi. Maka, Kompas TV tidak melewatkan hal itu demi memberikan konten "Eksklusif Digital" kepada khalayak. Dengan menggunakan kanal YouTube pun Kompas TV memberikan kesempatan kepada khalayak yang tidak menerima Kompas $T V$ dalam siaran terestrial, bisa menonton Kompas TV di YouTube dengan menghadirkan konten yang lebih bervariasi.

"Kenapa YouTube, pertama karena kita masih menggunakan player videonya YouTube. Lalu yang kedua secara traffic memang YouTube paling tinggi. Tetapi, kita juga punya di instagram di twitter, hanya karena basisnya video ya di YouTube dan website," (Wawancara peneliti dengan Yogi Nugraha, GM News \& Current Affairs Kompas TV pada 4 September 2017).

Pemilihan kanal website kompas.tv dan YouTube Kompas TV sebagai medium penyaluran konten "Eksklusif Digital" berdasarkan beberapa pertimbangan. Pihak Departemen Digital Kompas TV telah membuat kebijakan-kebijakan dalam pemilihan dua kanal media online tersebut. Selain itu, mereka melihat bagaimana peluang dan kesempatan dalam pemanfaatan kanal website kompas.tv dan YouTube sebagai medium pendistribusian konten "Eksklusif Digital". Hal itu diperlukan karena sebagai dasar untuk kemajuan "Eksklusif Digital" di kemudian hari.

Kompas $T V$ menanamkan konsep sebagai beyond television, yaitu suatu televisi nasional yang mendistribusikan kontennya melalui berbagai macam platform. Tidak hanya sebagai televisi nasional berjaringan, tapi juga melalui siaran televisi berbayar dan siaran digital melalui koneksi internet. Konsep beyond television itu sudah ada sejak Kompas $T V$ dibuat, tepatnya yaitu 
205 | Kajian Jurnalisme

ISSN 2549-0559 (cetak) ISSN 2549-1946 (online)

Volume 02 Nomor 02 Tahun 2019

sejak 2007. Di tahun itu pula, konsep digital berbasis internet Kompas TV sudah disiapkan, meski belum ada aturan mengenai standar produksi video dengan menyesuaikan produksi digital.

Dengan memiliki konsep beyond television ini maka Kompas $T V$ telah merancang masa depan, melihat kesempatan bagaimana pasar industri media di kemudian hari. Sebab, seiring perkembangan zaman, pasti akan ada perubahan perilaku konsumsi masyarakat terhadap informasi. Saat ini, masyarakat di Indonesia sudah mulai kecanduan menggunakan media online sebagai pemenuh kebutuhan informasi mereka. Melihat fenomena tersebut, Kompas TV membuat "Eksklusif Digital" sebagai sebuah strategi agar masyarakat masih bisa menikmati konten Kompas TV salah satunya dengan mengakses "Eksklusif Digital" di website kompas.tv dan YouTube Kompas TV.

Website kompas.tv dan YouTube Kompas TV memiliki peluang dan kesempatan yang besar dalam menarik khalayak untuk tetap mengakses Kompas $T V$ di era internet seperti saat ini. Menurut Yogi Nugraha, hal itu pun sebagai antisipasi ketika masyrakat mulai berpaling dari tontonan televisi, maka tawaran "Eksklusif Digital” Kompas TV inilah yang tepat untuk mereka.

"Sebagai televisi nasional berjaringan, kami sadari dari awal bahwa kami punya konsep beyond television. Kita merancang masa depan, kita melihat kesempatan. Ketika di tengah masyarakat ada perubahan perilaku konsumsi informasi ya harus kita ikuti. Kita jangan ga peduli, sekarang orang-orang menonton lewat internet, kita malah masih menggunakan antene, tidak boleh seperti itu. Lembaga penyiaran, institusi media, Kompas $T V$ termasuk Kompas Gramedia Grup yang memang memproduksi banyak konten juga harus punya kesadaran juga mengantisipasi pergerakan perubahan perilaku masyarakat dalam mengonsumsi media. Kalau sekarang kecenderungannya pada internet, mereka mau nonton lewat internet. Melihat situasi seperti itu, kita sebagai sistem kerja yang harus mengantisipasi. Kemudian Kompas TV sudah mengantisipasi pergerakan perubahan masyarakat yang sudah jarang menonton televisi dengan menghadirkan "Eksklusif Digital", karena Kompas TV melihat persis situasi di luar sana," (Wawancara peneliti dengan Yogi Nugraha, GM News \& Current Affairs Kompas TV pada 4 September 2017).

Dalam memilih kanal website kompas.tv dan YouTube Kompas TV sebagai medium penyaluran konten "Eksklusif Digital" memiliki target-target tertentu yang ingin dicapai. Terdapat tiga target yang ingin dicapai oleh Kompas TV melalui penyaluran konten "Eksklusif Digital" di website kompas.tv dan YouTube Kompas TV. Haris Mahardiansyah, Content Creator \& Video Distribution Superintendent dari Departemen Digital Kompas TV menuturkan bahwa target-target tersebut di antaranya, (1) variasi konten pada Kompas TV, (2) menarik khalyak untuk mengakses website kompas.tv dan meningkatkan jumlah penonton Kompas TV pada tayangan digital berbasis internet, dan (3) mendapatkan revenue tambahan.

Pertama, yaitu variasi konten. Dalam hal ini, Kompas TV melalui "Eksklusif Digital" pihaknya ingin menawarkan sesuatu yang beda dibandingkan dengan program-program Kompas

http://jurnal.unpad.ac.id/kajian-jurnalisme 
Kajian Jurnalisme

ISSN 2549-0559 (cetak) ISSN 2549-1946 (online)

Volume 02 Nomor 01 Tahun 2019

$T V$ pada siaran terestrial, serta stasiun televisi lainnya, khususnya yang fokus terhadap konten berita. Konten yang ditayangkan pada program-program "Eksklusif Digital” merupakan konten khusus yang hanya ditayangkan pada "Eksklusif Digital", artinya konten tersebut tidak ditayangkan pada siaran televisi terestrial. Topik yang dibahas pun ditentukan secara khusus oleh tim Departemen Digital, adapun jika akan membahas topik yang sedang ramai dibicarakan pada media massa, maka tim Departemen Digital membahasnya dengan mengambil sisi lain dari topik tersebut untuk ditayangkan pada "Eksklusif Digital".

"Kita ingin menawarkan satu hal yang berbeda dibandingkan dengan yang tayang di on air Kompas $T V$ nya sendiri, ataupun kita menawarkan ide yang berbeda dengan tv-tv berita lainnya, seperti Metro TV atau TV One. Mereka juga punya website, mereka juga punya channel di YouTube, tapi isinya kurang lebih sama. Mereka potong-potong beritanya lalu diunggah. Atau misalnya ada live streaming gitu. Apa yang membuat Kompas $T V$ itu berbeda sehingga orang gini, eh Kompas $T V$ ada yang lain lho, dan itu adalah "Eksklusif Digital", konten-konten yang tidak tayang di on air dan hanya tayang di website kompas.tv gitu," (Wawancara peneliti dengan Haris Mahardiansyah, Content Creator \& Video Distribution Superintendent Digital Departement Kompas TV pada 4 September 2017).

Lalu, yang kedua adalah menarik lebih banyak khalayak untuk mengakses website kompas.tv dan meningkatkan jumlah penonton Kompas $T V$ pada tayangan digital berbasis internet, khususnya pada program "Eksklusif Digital". Menurut Haris Mahardiansyah, dengan adanya "Eksklusif Digital" ini diharapkan dapat membuat khalayak menjadi penasaran dengan Kompas TV. "Eksklusif Digital" yang topik konten tayangan setiap harinya yang berbeda dengan tayangan pada terestrial Kompas $T V$ diharapkan bisa membuat penonton menjadi penasaran dan terdorong untuk bisa mengakses "Eksklusif Digital" melalui website kompas.tv. Masyarakat yang sekarang mulai meninggalkan tayangan tv konvensional pun bisa menjadikan "Eksklusif Digital" sebagai salah satu pilihan tontonan yang bisa dinikmati dengan mengakses website kompas.tv atau YouTube melalui gawai yang dimilikinya.

Terakhir, target yang ketiga adalah mendapatkan revenue tambahan. Sebagai industri media, tentu saja Kompas $T V$ membutuhkan banyak pengiklan untuk mendapatkan dana demi meningkatkan bisnis medianya. Selama ini, penghasilan Kompas TV paling banyak didapatkan melalui iklan-iklan yang ada di siaran terestrial Kompas TV. Maka dari itu, dengan mengelola "Eksklusif Digital" yang kontennya didistribusikan melalu website kompas.tv dan YouTube Kompas $T V$, mereka ingin mendatangkan sumber penghasilan baru. Apalagi salah satu kanal pendistribusiannya yaitu YouTube sedang berada di posisi puncak dalam hal penonton.

"Jadi kita ingin mendatangkan, mendapatkan revenue selain revenue iklan yang di on air. Nah, jadi ketika kita mengelola "Eksklusif Digital", harapan kita adalah ada brand atau klien yang mau dibuatkan materi iklan untuk di digital. Ya mendapat iklan tambahan yang kita dapat dari YouTube," (Wawancara peneliti dengan Haris 
Kajian Jurnalisme ISSN 2549-0559 (cetak) ISSN 2549-1946 (online)

Volume 02 Nomor 02 Tahun 2019

Mahardiansyah, Content Creator \& Video Distribution Superintendent Digital Departement Kompas TV pada 4 September 2017).

Website kompas.tv dan YouTube Kompas TV merupakan sebuah media massa online yang dimiliki oleh Kompas TV. Adanya website kompas.tv dan YouTube Kompas TV merupakan bentuk konvergensi media yang dilakukan oleh Kompas $T V$. Konsep konvergensi media bermula dari gagasan bahwa berbagai macam teknologi dan bentuk media hadir bersamaan. Konvergensi media digagas oleh Nicholas Negroponte dan Media Massachusetts Institute Technology (MIT) pada tahun 1979 (Fidler, 2003: 38). Pada buku "Mediamorfosis" karya Roger Fidler, Negroponte dan koleganya di MIT diyakini termasuk yang pertama kali mengakui bahwa konvergensi industri media dan teknologi digital pada akhirnya akan mengarah pada bentukbentuk yang dikenal sebagai komunikasi multimedia. Multimedia atau juga yang dikenal sebagai media campuran pada umumnya didefinisikan sebagai medium yang mengintegrasikan dua bentuk komunikasi atau lebih.

Kaitannya dengan penelitian ini, Kompas $T V$ melakukan proses mediamorfosis berupa konvergensi media berdasarkan konsep konvergensi media yang menganggap berbagai macam teknologi dan bentuk media hadir bersamaan. Dalam hal ini, teknologi penyiaran dan teknologi internet membuat sebuah media yang berintegrasi, yaitu stasiun Kompas TV, website kompas.tv, dan YouTube Kompas TV. Meski berbeda saluran, mereka hadir bersamaan karena masih di bawah satu naungan yang sama.

Kemudian, website kompas.tv merupakan jenis dari new media yang diterapkan oleh Kompas TV. Terdapat tiga karakteristik new media:

1. Sudah masuk ke era digital, yang kemudian memungkinkan perbedaan format media itu menjadi samar seperti antara cetak dan elektronik, karena keduanya dapat dilewatkan melalui saluran yang sama.

2. Sudah mempunyai sifat interaktif.

3. Sudah tidak mengenali lagi batas-batas wilayah negara.

Website kompas.tv masuk sebagai new media karena termasuk dalam karakteristik tersebut. Pertama sudah masuk ke era digital, hadirnya website kompas.tv memang sudah masuk ke era digital seperti saat ini dan website kompas.tv pun untuk diakses melalui digital berbasis internet, konten-kontennya pun berupa konten digital, termasuk program-program "Eksklusif Digital".

Kedua, mempunyai sifat interaktif, melalui tayangan yang ada di website kompas.tv khususnya tayangan "Eksklusif Digital" masyarakat dapat memberikan respon langsung ketika mereka menyukai atau tidak menyukai konten yang ditayangkan, hal itu sebagai bentuk interaktif. Serta yang ketiga yaitu sudah tidak mengenali lagi batas-batas wilayah negara.

http://jurnal.unpad.ac.id/kajian-jurnalisme 
Kajian Jurnalisme

ISSN 2549-0559 (cetak) ISSN 2549-1946 (online)

Volume 02 Nomor 01 Tahun 2019

Website kompas.tv ini karena diakses menggunakan internet, maka khalayak dari manapun bisa membuka kanal tersebut, tidak adanya batasan ruang dan waktu.

Kanal lainnya yang digunakan sebagai sarana penyaluran konten "Eksklusif Digital" adalah YouTube. Memilih YouTube, karena saat ini khalayak lebih sering mengakses YouTube dibandingkan dengan tayangan televisi terestrial untuk melihat berbagai tontonan, baik yang sifatnya berita maupun yang bukan. Hal itu diperkuat dengan ungkapan CEO YouTube Susan Wojcicki, ia menuturkan pada tahun 2017 ini penonton YouTube lebih banyak daripada penonton televisi Indonesia. Jumlah penonton YouTube di usia 18 hingga 49 tahun berhasil mengalahkan jumlah penonton di rentang usia yang sama di platform lain, baik siaran televisi konvensional ataupun siaran televisi kabel. Menurutnya, mereka berhasil menjangkau penonton berumur 18 hingga 49 tahun lebih banyak daripada total penonton yang dicapai oleh 10 acara TV terpopuler. (http://m.metrotvnews.com/teknologi/news- teknologi/Obz9BJeN-bos-youtube-penonton-tvberkurang-penonton-kami-bertambah diakses pada 4 Juli 2017)

Selain itu, menurut Managing Director Google Indonesia, Keusgen, yang dilansir dari kumparan.com, selama satu tahun, sejak Januari 2016 hingga Januari 2017 durasi menonton YouTube dari Indonesia meningkat 155 persen. Sementara jumlah konten yang diunggah dari Indonesia naik hingga 278 persen dari tahun lalu. Konsumsi video juga diprediksi akan naik tujuh kali lipat pada 2020. Adapun pertumbuhan durasi tonton dan jumlah konten tersebut, tentu dibarengi dengan pertumbuhan pendapatan YouTube dari konten iklan video di Indonesia, di mana belakangan ini semakin jelas terlihat banyak pemegang merek dan produk yang menyisihkan uangnya untuk distribusi konten iklan di YouTube (https://kumparan.com/jofieyordan/google-durasi-tonton-dan-jumlah-konten-YouTube indonesia-tumbuh-pesat). YouTube juga merupakan media sosial teraktif yang digunakan di Indonesia menurut wearesocial.com, dibandingkan dengan media sosial lainnya seperti facebook, instagram, twitter, whatsapp, google + , fb messenger, line, linkedin, bbm, pinterest, dan wechat.

Pilihan yang tepat jika Departemen Digital Kompas TV menggunakan YouTube sebagai media penyaluran konten "Eksklusif Digital" Kompas TV karena YouTube merupakan media sosial yang memiliki jumlah penonton yang tinggi dibandingkan dengan jenis media sosial lainnya, khususnya di Indonesia. Hal itu telah dibuktikan oleh banyak pihak. YouTube ini pun bisa disebut sebagai bentuk new media yang dimiliki Kompas TV selain website kompas.tv. Hal tersebut berdasarkan karakteristik dari new media yang telah dipaparkan sebelumnya.

Pertama yaitu sudah masuk ke era digital, YouTube berkembang pesat karena adanya era digital berbasis internet yang memudahkan masyarakat untuk bisa mengakses segala informasi dari belahan dunia manapun. Meskipun konten "Eksklusif Digital” Kompas TV ini diproduksi di Indonesia dan Jakarta, tapi seluruh orang bisa mengaksesnya melalui YouTube. Kedua adalah mempunyai sifat interaktif. Sama halnya dengan webisite kompas.tv, khalayak yang menonton tayangan "Eksklusif Digital" dapat memberikan respon langsung pada video tersebut, seperti 
menyukai atau tidak menyukai tayangannya. Selain itu, pada YouTube memiliki kolom komentar, sehingga khalayak jika ingin memberikan saran atau mengomentari mengenai konten program, bisa langsung melalui kolom komentar. Tak hanya khalayak saja yang bisa berkomentar, pihak dari Departemen Digital pun dapat membaca bahkan merespon komentar dari khalayak meski tidak semuanya.

"Ada yang kita respon, tapi ada juga yang kita biarkan. Kenapa kita biarkan, karena sering ada komentar-komentar negatif bahkan kasar, maka yang kita lakukan sesuai dengan manajemen adalah untuk menghapus komentarnya. Tetapi kalau misalnya kritikan itu bentuknya masih normatif, biarin saja tidak perlu dibalas. Sebab, nanti misalnya ada 50 komen, 10 orang komentarnya negatif pasti nanti sisanya ada 40 orang yang akan membela, jadi saling saut-menyaut pada komentar. Nah, itu dibiarkan saja, karena semakin banyak yang komen artinya video lo semakin banyak yang nonton," (Wawancara peneliti dengan Haris Mahardiansyah, Content Creator \& Video Distribution Superintendent Digital Departement Kompas TV pada 4 September 2017).

Kemudian yang ketiga adalah tidak mengenali lagi batas-batas wilayah negara. Dengan diakses melalui layanan internet, maka semua orang dapat mengakses YouTube yang memuat konten "Eksklusif Digital". Sehingga, masyarakat dari manapun ia berada dapat mengakses konten "Eksklusif Digital" yang disalurkan melalui YouTube.

Telah diketahui jika saat ini masyarakat yang mengakses media sosial lebih tinggi dibandingkan dengan mengakses media massa konvensional untuk memenuhi kebutuhan akan informasi. Berdasarkan data dari Asosiasi Penyelenggara Jasa Internet Indonesia (APJII), jumlah khalayak yang mengakses media sosial lebih tinggi daripada khalayak yang mengakses berita, yaitu sebanyak $97,4 \%$ atau 129,2 juta orang mengakses media sosial, sedangkan pengakses berita adalah 96,4\% atau 127,9 juta orang. Oleh karena itu, industri media massa, termasuk Kompas TV menyiasatinya dengan memanfaatkan media sosial, termasuk YouTube sebagai sarana untuk penyaluran informasi yang mereka produksi agar dapat menjangkau khalayak lebih luas.

Berdasarkan hasil penelusuran online dan studi pustaka lalu menganalisis dengan hasil penelitian di lapangan, menurut peneliti bahwa pemilihan kanal website kompas.tv dan YouTube sebagai medium penyaluran konten "Eksklusif Digital" sudah tepat. Pertama, di lihat dari sisi website kompas.tv, tujuan menyalurkan konten "Eksklusif Digital" yaitu ingin memperkenalkan website kompas.tv kepada khalayak. Khalayak yang saat ini cenderung lebih sering mengakses internet, dibandingkan media massa konvensional, membuat kesempatan website kompas.tv untuk dikenal khalayak luas kemungkinannya besar. Lalu, dengan menghadirkan "Eksklusif Digital" yang konten programnya cenderung membahas mengenai sesuatu yang sedang ramai diperbincangkan di kalangan masyarakat dan pengemasan konten yang lebih santai, menarik, dan menyesuaikan dengan video-video yang ada pada digital, hal itu membuat mendorong khalayak untuk menonton konten-konten "Eksklusif Digital" yang tentunya diakses melalui website http://jurnal.unpad.ac.id/kajian-jurnalisme 
Kajian Jurnalisme

ISSN 2549-0559 (cetak) ISSN 2549-1946 (online)

Volume 02 Nomor 01 Tahun 2019

kompas.tv. Dengan demikian, website kompas.tv akan lebih terkenal di kalangan masyarakat sebagai website video portal dari Kompas TV.

Kedua, dilihat dari sisi penyaluran konten "Eksklusif Digital" Kompas TV melalui kanal YouTube. Berdasarkan data dari Asosiasi Penyelenggara Jasa Internet Indonesia (APJII) bahwa pengguna internet Indonesia lebih sering menggunakan internet untuk mengakses media sosial. Lalu berdasarkan data wearesocial.com bahwa YouTube merupakan platform media sosial yang paling banyak digunakan di Indonesia. Dengan demikian, Departemen Digital Kompas TV sudah tepat menggunakan YouTube sebagai salah satu strategi penyaluran konten "Eksklusif Digital" Kompas $T V$, dibandingkan dengan menggunakan platform media sosial lainnya berdasarkan data-data dan analisis yang telah dijelaskan.

Selain itu, pertimbangan Kompas TV membuat "Eksklusif Digital" yang kontennya disalurkan melalui kanal website kompas.tv dan YouTube adalah ketika melihat segmentasi mereka, yaitu mengarah pada khalayak dengan usia 15 hingga 40 tahun sekian, merupakan sebuah keputusan yang tepat, karena berdasarkan data survey Asosiasi Penyelenggara Jasa Internet Indonesia (APJII) pada 2016, tercatat pengguna internet di Indonesia pada usia sekitar 15 hingga 44 tahun adalah 72,0\% atau 95,4 juta orang. Maka, target untuk mencapai khalayak kisaran usia 15 hingga 40 tahun bisa dilakukan oleh "Eksklusif Digital” Kompas TV.

\section{Simpulan}

Kebijakan utama Kompas TV memilih kanal website kompas.tv dan YouTube sebagai sarana untuk menyalurkan konten "Eksklusif Digital", karena website kompas.tv merupakan platform utama Kompas TV pada media online (dalam jaringan). Webite kompas.tv merupakan bentuk konvergensi media yang dilakukan oleh Kompas TV, dengan begitu melalui "Eksklusif Digital" dapat memperkenalkan website kompas.tv kepada khalayak sebagai video portal Kompas TV. Lalu, memilih YouTube, karena memang pengunjung YouTube saat ini adalah yang paling tinggi. Maka, Kompas TV memanfaatkan hal itu untuk menyalurkan konten "Eksklusif Digital" kepada khalayak.

\section{Daftar Pustaka}

Denzin, N.K. \& Lincoln . 1994. Handbook of Qualitative Research. Thousand Oaks, CA: SAGE.

Fidler, Roger. 2003. Mediamorfosis. Yogyakarta: Bentang.

Moleong, Lexy J. 2007. Metodologi Penelitian Kualitatif: Edisi Revisi. Bandung: PT Remaja Rosdakarya.

Stake, Robert E. 2010. Qualitative Research: Studying How Things Work. New York: The Guilford Press.

Sugiyono. 2012. Metode Penelitian Kuantitatif Kualitatif dan R\&D. Bandung: Alfabeta.

Sugiyono. 2014. Metode Penelitian Manajemen. Bandung: Alfabeta.

Werner, J. Severin, et al. 2008. Teori Komunikasi: Sejarah, Metode, dan Terapan di Dalam Media Massa. Jakarta: Kencana, Prenada Media Group.

http://jurnal.unpad.ac.id/kajian-jurnalisme 
211 | Kajian Jurnalisme ISSN 2549-0559 (cetak) ISSN 2549-1946 (online)

Volume 02 Nomor 02 Tahun 2019

Yin, Robert K. 2014. Studi Kasus: Desain \& Metode. Jakarta: PT Rajagrafindo Persada.

\section{Website}

http://m.metrotvnews.com/teknologi/news-teknologi/Obz9BJeN-bos-youtube-penonton-tv-berkurangpenonton-kami-bertambah (diakses pada 4 Juli 2017 pukul 12:00 WIB)

https://kominfo.go.id/content/detail/4286/pengguna-internet-indonesia-nomor-enamdunia/0/sorotan_media (diakses pada 4 juli 2017 pukul 12:15 WIB)

https://wearesocial.com (diakses 5 September 2017 pukul 14.33 WIB)

https://www.kompas.tv/content/category/12/exclusive\%20digital

www.apjii.or.id (diakses pada 5 September 2017 pukul 20.16 WIB)

https://kumparan.com/jofie-yordan/google-durasi-tonton-dan-jumlah-konten-YouTube-indonesia-tumbuhpesat (diakses 6 September 2017 pukul 20.45 WIB)

http://jurnal.unpad.ac.id/kajian-jurnalisme 